Matti Sintonen

\title{
Basic and applied sciences - can the distinction (still) be drawn?
}

\section{Introduction}

The bifurcation between basic and applied science is commonly taken as one of the grand lines that divide and serve to classify types of inquiry. It plays an important role in science policy and administration, as is indicated by the often heard complaint that basic inquiry has suffered from inadequate attention and financial support. Yet many scientists have voiced doubts about the very existence or at least applicability of the distinction. The endresult is slightly schitzophrenic, and occasions in a philosophy student a déja-vu-experience: not long ago was the distinction between "meaning-based" analytic and "factual" synthetic truths, one of the dogmas of empiricism, denied intelligibility. Yet, although the distinction is hard to define, we seem to be at loss without it - it is simply needed. An analogously troublesome if not outright inconsistent stance was already detectable in the OECD report of 1966 which more or less underlies more recent discussions: OECD found it important to secure adequate financial and other support for basic research, but admitted that "the distinction cannot always be clearly drawn" and that this task is becoming ever more difficult (OECD, 1966: 15).

I shall take it for granted that there is a distinction of a sort between basic and applied research. Yet there have been surprisingly few attempts to say exactly where the borderline runs, and even fewer theoretical attempts to explain why it runs where it is supposed to run. As a modest constructive step I shall first examine some difficulties and limitations in two general ways to draw the distinction, and then attempt to overcome some of them in what I term the umbrella model of inquiry. The main import of the umbrella model is in that it gives up attempts to locate the distinction on the level of academic fields or disciplines, or between university departments, faculties, research institutions, or other administrative units. Rather, the model takes seriously an idea which has again surfaced in philosophy of science, the idea that inquiry is search for answers to various types of questions. Roughly, the umbrella model locates the distinction on the level of research questions and not the fields or disciplines in which these questions 
arise.

As an aside we receive some light on another distinction which has come to play an equally prominent role in the classification of types of inquiry, that between monodisciplinary and interdisciplinary inquiry. Although the model only gives a relatively crude image of applied interdisciplinary inquiry, this image nevertheless is more adequate than that given in traditional philosophy of science concerned with the 'rational reconstruction' of monotheoretic basic inquiry.

\section{Motivation vs. Logic}

But let us start with some stage setting. There are, roughly, two opposing ways to draw the distinction between basic and applied science: one can start with the motivation of the inquirers (or financers or policy makers), or one can attempt to find systematic differences in the logic, methodology, and aims of the two types of inquiry.

The first way was OECD's, although the roots of the idea reach back to the 19th Century at least. According to OECD's classic characterization, research and development can be divided into basic or fundamental research, applied research, and development. Basic research aims, in this view, at the extension of scientific knowledge, of "increasing our understanding of nature" (OECD, 1966: 15). This OECD report also made explicit the idea that basic inquiry is best characterized in terms of motives for inquiry rather than research techniques. Thus we can read from the 1966 report that "fundamental and applied science are perhaps most easily distinguished today in terms of motivation rather than differences of nature or technique - the aim of fundamental research is extension of knowledge for its own sake, that of applied research the utilisation of existing knowledge." Questions of motivation could, in turn, pertain to different levels: on individuals, groups, or higher entities. Accordingly, the question "Whose motives?" can be given different answers. But whatever the motive-bearer is, the distinction is in principle clear: basic inquiry is interested in knowledge for its own sake, while applied inquiry is interested in finding knowledge that is useful for extrascientific purposes.

There is of course no consensus over what scientific knowledge exactly is, but the following minimal basis suffices for discussion purposes: it resides in viewpoints, research programs and especially theories which manifest purely cognitive objectives or desiderata, such as truth, information content, and explanatory power, as well as such "aesthetic" virtues as simplicity and conceptual economy, i.e., the mastery of a wide variety of areas by a minimum of conceptual apparatus. To give a working definition, let us then say that basic research is search of knowledge for its own sake, and thus aims at the maximization of cognitive desiderata.

Applied research is also pursuit of knowledge, but here the goal is, in OECD's words, to attempt "to put to use the findings of basic research or even to discover new knowledge which might have immediate practical application." This characterization is loaded with interpretative issues. Leaving aside "immediate", I shall say a few words about "application", and a bit more about "practical". Focusing on applications cuts no philosophical ice, because paradigm examples of theories in basic research have been designed for intended applications. Thus for instance classical particle mechanics has different kinds of intended applications, from gravitation phenomena to electro-magnetic phenomena. However, intended applications in basic science arise from the purely descriptive and explanatory perspective of telling how things are and why they are the way they are.

In applied research proper applications are singled out by other than purely cognitive goals. The deterioration of the environment can be considered a problem which is, to put it mildly, not a merely academic one. Consequently, promoting the well-being of the environment gives a practical goal and hence an extra-scientific criterion of relevance for what counts as an answer or a good answer: goodness depends on how well the answer serves to promote the practical desideratum.

One drawback in the OECD characteriza- 
tion is that its reference to practical applications remains sketchy. Furthermore, as Ilkka Niiniluoto (1987) has observed, pragmatic contextual criteria refer to limited times and places. He lists some of these features and finds them all indeterminate and even inconsistent: the inquirers' own views (an inquirer in applied research has in mind the practical applications of the knowledge), the inquirers' personal motives (in basic science curiosity, in applied science usefulness), the intentions of the financer (applied sciences are supported because of their practical utility), research sites (basic sciences are located in the universities, applied ones mostly in private research laboratories and in the industry), and in the speed at which the results of research can be made use of (strategic basic science leads to practical applications in the long run whereas oriented research leads to them in the short run).

The main difficulty in the way of an adequate non-pragmatic account is the fact that our metatheories have been designed with an eye on such basic sciences as mathematics, physics, astronomy, biology, psychology and sociology. However, Niiniluoto (1987) notes that it is far from clear that notions of science based on the model of basic sciences do justice to the peculiar nature of such applied fields and sciences as mathematics, shipbuilding, horticulture, forest technology. The former are characteristically monotheoretic and monodisciplinary in which problem choice and the assessment of solutions is governed by the conceptual needs of single theories and research traditions. The latter are, to use a phrase employed by Slobodkin (1988), intractable sciences in which it is usually not clear what the next important problem to solve is. I shall try to give a reason why applied sciences are intractable in section 4.

What Niiniluoto is after is an account based on systematic non-pragmatic features. He notes two types of features as potential candidates: first, the utilities which provide the touchstones for assessing progress and rationality in inquiry, and, secondly, the differences in the structure of knowledge. In some applied sciences - the design sciences - the end results can be expressed as technical norms which specify more or less efficient means to extrascientifically important goals. ${ }^{1}$

The differences can be appreciated by contrasting basic science and technical research. The task of basic sciences is to produce, by help of the scientific method, new knowledge of what the world is, and its utilities are such epistemic utilities as information and truth. Technology, that is, design and manufacture of new products and methods cannot be assessed by epistemic but rather practical utilities because the artefacts created are not true or informative linguistically formulated results. Applied sciences fall, in Niiniluoto's view, between the two. On one hand their results can be assessed on the basis of epistemic utilities, on the other hand the knowledge sought after has some intended practical applications, usually the more efficient carrying out of a technical activity (broadly understood), such as accounting, shipbuilding, forestry, milk production, etc.

\section{A Troubled Distinction}

I find Niiniluoto's analysis largely compelling Yet neither it nor OECD's definition gives quite an adequate account of the fairly complex goings-on in research. One shortcoming pertains to the level on which the distinction is drawn. I shall try to argue that the proper level is not that of fields, disciplines or research units. Another complication has to do with the intractability and interdisciplinary nature of much applied research.

Note, first, difficulties in assessing motivations for engaging in and supporting inquiry. OECD exists, according to its charter, to promote "the highest sustainable economic growth and employment and a rising standard of living in Member countries...". OECD has always been a keen supporter of fundamental or basic research, but the reason given in the report (OECD, 1966: 19) is slightly surprising: "The value of fundamental research in contributing to man's understanding of the universe and of himself is self-evident." I share the view that knowledge and understanding have intrisic 
value, but find it hard to believe that basic research is in special favour because knowledge is fun or valued as an end.

To illustrate mixed institutional motivations, consider the verdict of the Pound Committee which investigated United States agricultural research (see Wade, 1973:390). The committee observed that some outstanding basic research had been conducted in the USDA [U.S. Department of Agriculture] labs, but faulted agriculture for "neglecting its responsibilities even in fundamental problems of primary concern to its mission, such as photosynthesis and nitrogen fixation", which had been left to private and state universities and other research institutions. According to two panelists of the report, "those responsible for research administration in agriculture have minimized the importance of photosynthesis, which the panel considers to constitute a "shocking lack of intellectual leadership". "The tenor here is that some basic research is and should be relevant to agriculture, and that research institutions designed for applied inquiry also face legitimate fundamental problems. Actually, it does not make sense to say that USDA should support agriculture unless one thought that this basic research is useful for agriculture. For that must be the rationale for having basic research in an institute with an unabashedly applied mission.

How should we understand motivation? Of course here the question as to whose motivations are at stake is important. An individual inquirer involved in basic research may well think that the game of maximizing epistemic utilities is fun, and suffices by way of motivation. But it would be naive to think that the game would receive as much institutional support if this were the case. The view that also the institutional motivation of basic research flows from its potential usefulness in the hands of technology and industry at large fits well with the way modern science of science looks at matters. Just to take innovation research as an example. The traditional linear model of the innovation chain starts with the idea that basic research gives rise to applied research and then to development, and thus results in innovations and technical develop- ment, and finally in economic growth. Although empirical results in the sixties were mixed, the idea nevertheless was that future innovations depend in an increasing degree on basic research done today.

The model has come under fire, and the consensus seems to be that the linearity assumption is simplistic, not to speak of other assumptions. Yet, it can hardly be denied that basic science is important for innovations, technological progress and economic growth. And all I am saying here is that this makes it plausible that the real motivation for investing in basic research on a massive scale is not that knowledge is fun, but that knowledge is useful. What we have here is, to usea a distinction drawn by Sylvain Bromberger (1984: 312), two types of value which might accrue from answers to basic questions, gosh value and cash value: "gosh value is a measure of the intellectual pleasure we derive from coming to know an answer", whereas "cash value is a measure of the material benefits an answer puts at our disposal". The flourishing of basic inquiry is, then, in part at least a result of a happy coincidence in which individual inquirers' maximization of gosh value and institutional maximization of cash value produce outputs that benefit both - though of course the institutional maximizer cannot tell in advance where and when the results can be harvested. By this suggestion I do not mean to imply that the treasurer's viewpoint extends to all basic research so-called, such as, say, basic research in the humaniora.

Third, OECD's characterization as well as the linear innovation model take it for granted that applied sciences typically utilize existing knowledge. Although OECD softens this remark by adding that applied sciences nevertheless aim at new knowledge, there is the implication that basic sciences are less constrained by results already achieved. This view may well be behind the popular (and denigrating) perception of some sciences being theoreticall:' inferior or undeveloped. But this perception is unfair and the whole distinction untenable: normal scientific work in mature basic sciences typically relies on an existing disciplinary matrix, with a more or less rigid 
conceptual cutlery. And as Thomas Kuhn in particular has emphasized, in normal-scientific puzzle solving much of the existing knowledge is above criticism. Actually of course all sciences apply existing knowledge in the search of new knowledge: whether (allegedly) applied or basic, initial insights must be developed, by help of a series of non-trivial steps, to meet the demands of the intended application.

Fourth, the scope of the distinction, as it is now drawn, is understood to apply to academic disciplines, fields or even faculties. Thus theoretical physics and inorganic chemistry are said to be basic, so is economic theory and cognitive psychology. In contradistinction to this, technical sciences, paedagogic sciences, forestry science, much of jurisprudence, etc. is applied. However, it is an illusion to think that fields of inquiry, departments, faculties or disciplines can be so distributed. More and more of the topics chosen in traditional institutions on applied research have a theoretical angle and vice versa: researchers in universities and other traditional sites of academic research choose targets that bear potential applicational value (Bromberger's cash value).

Finally, it might be thought that although the distinction cuts across disciplines and administrative units it nevertheless can be used to classify individual research projects. But even this is overly simplistic. Although project descriptions may specify either basic of practical aims, they are helpless on the level of specific research question: it is often impossible to figure out, from a research question itself, whether it was motivated by practical or the oretical concerns. What often happens is that there is a practical question, say, of finding out how to prevent algal blooms, but the answer to this question requires research that is purely basic by any reasonable criterion. Thus there clearly can be basic subquestions in an applied project where it is immaterial to professional research concerns what the initial practical problem was. Conversely, although, e.g., studying photosynthesis is easily motivated through purely cognitive objectives, their applications to agricultural and forestry scien- ces (and elsewhere) are readily identifiable, and it consequently makes little sense to say that all work done on the topic is either applied or basic.

\section{The Umbrella Model of Inquiry}

Is there a framework which could create order into this messy picture? The strategy I favor is mixed, in that it acknowledges the importance of research motives, and yet concedes Niiniluoto his point: the systematic way to draw the distinction must take note of the utilities that define the goals in a type of inquiry. I shall present the basic idea in what I call the umbrella model. I here have just schematic pictures of basic and applied research so-called.

The Umbrella Model of Types of Inquiry

Basic research:
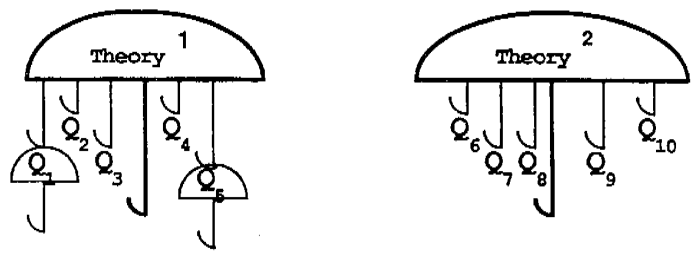

Applied research:
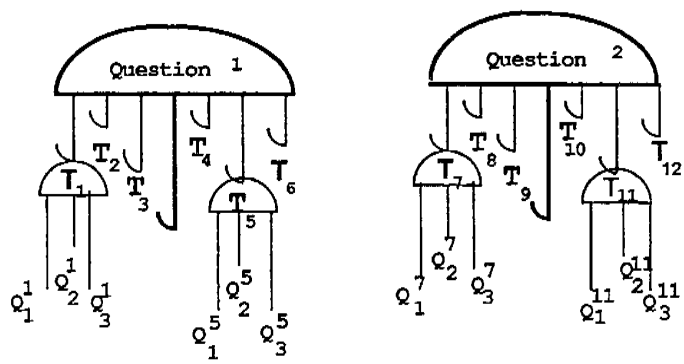

Here the upper part of the picture represents basic (monotheoretic) research where there characteristically are relatively autonomous theories (viewpoints, paradigms, 
maxitheories, models) which structure their problem areas. Here the research questions for Theory 1 are $Q_{1}-Q_{5}$, and for Theory $2 Q_{6}-$ $Q_{10}$. The lower half of the picture represents applied research in which the range of questions is selected by help of non-cognitive criteria, that is, the main relevance criterion for questions is not the purely theoretical one of filling in gaps whose sizes and shapes are moulded by the motivation of finding truthlike and elegant representations of a range of problems.

Both basic and applied inquiry fit the interrogative view of inquiry in which the landmarks on the way to knowledge are questions. I shall assume that research, both basic and applied, is systematic and goal directed activity which can be represented as a questioning-answering process. Roughly, an inquirer formulates some general or specific how-questions, explanation-seeking why-questions, and specific yes-no-questions (hypotheses concerning potential answers), and attempts to get answers that satisfy certain desiderata. The umbrella model takes as crucial the factors which motivate or prompt the initial questions: in basic research the motivation is theoretical or purely cognitive, whereas in applied research also extra-theoretic or non-cognitive ones enter: the promotion of moral, political, social, economic, and other practical aims.

The point of view is recognizably cognitivist, in that cognitive and conative aspects are kept separate. Although a practical decision-maker may use scientific information to assess the potential outcomes of various courses of action, and although there can be debates about what knowledge is, cognitive values attach to potential answers (knowledge claims) independently of their expected value in practical problem solving.

But to go back to the main distinction in the umbrella model. The metaphor I want to use is that in basic research, theories (viewpoints, paradigms, maxitheories, models) are the umbrellas under which relevant cognitive questions gather. In still other words, although search for knowledge is guided by research questions, questions receive their identities through a theory: they mark gaps in available representations of a problem area. In that sense basic monotheoretic research is theorydriven. Applied questions, in contrast, are motivated through extratheoretical ends, and hence inquiry is problem- or question-driven. To employ the metaphor, problems or questions singled out by extratheoretic concerns are the umbrellas under which relevant generalizations, theories and models meet.

Let me single out some consequences of the umbrella model. First, some of the cognitive values and methodological standards differ in applied research from those in basic research. Time and money are of course always in short supply, but these limitations are highlighted in applied research where answers cannot always wait for breakthroughs. Consequently, some of the cognitive criteria are different or relaxed. Take simplicity and cognitive economy as examples. Theoretical basic inquiry aims at maximally truthlike and unified accounts of (parts of) the world, and theories which contain a few basic principles to cover a large range of intended applications are desirable targets. However, cognitively speaking ideal fundamental theories are often maddeningly complex to apply. Although theoretically elegant and pleasing to the mind, a theory which gives a maximally detailed and general answer may be too demanding for a being with a finite memory and finite information processing capacities. This is why the whole truth may be too much, and why practical applications often settle for knowledge which is suboptimal by purely cognitive criteria. This marks a difference not just in the utilities sought but also in the methodological standards, because in applied inquiry the inquirer is a decision-theoretic satisficer and not a maximizer of epistemic utilities. ${ }^{2}$

Secondly, to overcome the shortcomings of the received distinction we must note that the level of generality of questions becomes important. Basic innovations start their careers as vague descriptive and explanatory how- or why-questions, but must be cultivated into specific research questions. This cultivation is only posible in terms of a framework and theories or, more desirable still, theoretical models with specific parameters and variab- 
les. Theoretical research projects are thus needed to give rise to specific questions. This means that underneath a basic umbrella there are "small" questions which obtain their identity from the viewpoint of the big umbrella. Similarly, applied projects start their careers in broadly circumscribed practical goal descriptions ("How can one prevent algal blooms?"), and also here the most important task is the processing of small questions which arise around rival potential answers. However, although there often are guiding theoretical insights behind the generation of the research questions, there need be no unique framework which could define them.

\section{Mixed Interests.}

This many-layered way of organizing questions is a built-in feature in the umbrella picture. Its most drastic import is that it allows us to see how basic and applied interests can get mixed in actual inquiry - even in a single research project. Thus under a big applied umbrella generated, say, by the practical interest of finding an antedote to a practical hazard, there can be small umbrellas that are motivated by a purely cognitive interest. For instance the big initial Question 1 has underneath it theories or rather viewpoints $T_{1}-T_{6}$, but deriving a workable answer to this big question may involve finding answers to theoretically motivated "small" questions under any one viewpoint, say $T_{6}$. Big applied questions are always amenable to treatment by several more specific viewpoints of theories, and these can generate more narrowly defined theoretical questions. This means that an inquirer in an applied project can face research questions which arise from the demands of the theoretical viewpoints. Analogously with theoretical umbrellas. A theory or theoretical model initially developed with a purely cognitive interest may suddenly offer its virtues to practical application. The result may be a small applied umbrella (or several applied small umbrellas) under a big initially basic umbrella. And of course, at this levels the cognitive constraint of maximum trutrlikeness may give way to a practically manipulable system of models, that is, models where the parameters are limited in number, and values for the variables and constants obtainable.

This explains why it is both legitimate and often necessary to let theoretical subprojects flourish in by and large practically motivated fields, disciplines or even research projects. Similarly, it explains why theoretical basic sciences in some fields at least produce practical applications. Finally, it explains why the received distinction based on motivations and research sites does not work. To employ a visual metaphor suggested by the umbrella pictures, an inquirer under a small umbrella may not see - or care - what is going on above the small umbrella.

Take ecology as an example. Theoretical ecology is a natural-scientific field with distinctly cognitive interests behind its questions concerning, e.g., the factors which influence the sizes and distributions of populations. The questions characteristically include explanatory whys and hows: why is this particular species so abundant in certain areas? How do members of certain species react in such and such circumstances? Applied ecology in turn studies organisms of practical importance and attempts to use the theoretical insights and empirical concerns of theoretical ecology in the solution of specific problems of environmental management. There is no end to problems in the field, and hence increasing amount of work to do in environmental conservation (and engineering) and other areas: green house gases change the climate and acid rains flood the soil, with large but in detail unforeseeable consequences to lakes and forests; human intervention and expansion destroys habitats, with the consequence that some species are becoming rare and extinct (while others flourish).

Consider then how the problems are selected in the two types on inquiry. In theoretical ecology the problems are determined through the hows and whys which arise from the cognitive demands of understanding complex interactions. However, in practical ecology the interests are varied, because what constitutes an environmental problem depends in part on 
popular perception. As Slobodkin observes, the California condor and the bald eagle have become environmental problems in the United States in part because of their symbolic value. And there may of course be conflicting interests in applied ecology, which explains why there need be no consensus as to whether something is a problem or not. Since big problems are not defined on the basis of any theory, applied ecology is not theory-driven the way theoretical ecology is. Slobodkin's example is deserts: turning agricultural land into a desert is commonly thought of as an environmental tragedy. On the other hand, since deserts often symbolize romantic freedom, transforming a desert into a green garden can be looked upon both as a triumph of the human spirit over untamed nature and as desecration of nature itself. (Slobodkin, 1988: 337).

Ecology also illustrates the vicissitudes of the basic/applied - distinction. As an example, take Slobodkin's description of his investigations of red tides on the Florida coast. The citizens of Florida were annoyed and the tourist industry alarmed by the dead and decaying fishes washed ashore. The clients wanted something (a cure, analogous to a pill) which, when added to water, would do away or diminish red tides. The primary result of the study was not a practical solution but "a general mathematical model of the growth of plankton blooms in discrete water masses diffusing at their boundaries", which served to explain, in part, when and where red tides occur. Consequent development of the model enabled predictions on an array of phenomena, from open ocean plankton blooms to the migration paths of whales. However, although the questions had great gosh value, leading to important theoretical gains (answers to whys and hows), they did not have sufficient cash value in the form of a workable prescription. Thus there grew up, under the big umbrella initially erected for an applied question, smaller umbrtellas with clearly theoretical contours.
To finish the list of features of the umbrella model, note that it also makes graphic sense of a phenomenon which is familiar to those who deal with applied questions, viz., the interdisciplinary nature of the initial Fragestellung. Where the big initial questions are motivated through practical needs it is natural that not all potential answers are tied to this or that particular theory, approach or viewpoint. A big question does not as such specify what conceptual equipment the answer should have. This means that much of applied research is theoretically eclectic: although the generation of potential answers involves focussing on a particular approach, rivals are abundant, and no approach is a priori illegitimate. (See Sintonen 1990).

Consider again ecological research as an example. Theoretical ecology already touches questions from the physiology and behavior of individuals and groups to population dynamics and community ecology, and consequently needs either direct access or consultant help from a range of allied disciplines (See, e.g., Roughgarden, May and Levin, 1989: 4). To employ a phrase coined for evolutionary theory, ecological theory appears to be more of a treaty than a well-circumscribed single theory (see Burian, 1990). This means that the umbrella image for basic science must be taken with a grain of salt: the specific theories and models that comprise theoretical ecology are not literally self-sufficient but require cooperation. These complexities are magnified in applied ecology, for reasons already hinted at. One reason is that theory-centered strictures are even weaker here. Another one is that in practical applications, say, in resource management and conservation biology, also non-biological viewpoins (e.g. that of economy) have a say. The upshot is that ecology does not focus on a couple of theoretically central (and "feasible") problems at a time. As Slobodkin (1988: 338) puts it, "ecology may be the most intractable of all legitimate sciences ever developed". 


\section{NOTES}

1. Applied research aims at directives or technical norms which differ from categorical norms in that they are true or false conditional norms or recommendations concerning the suitability of a means to an end. Technical norms of the form "If you want to achieve a practical goal $Z$, in a situation $X$ you (one) should do $Y$ " are recommendations concerning a choice of means to a goal: the means should be sufficient to the attainment of the goal, or at least it should make its attainment probable (or more probable).

2. Ronald Giere (1988: 157-165) has suggested, following Herbert Simon, that, since there also are in basic inquiry sometimes conflicting values which can be weighed differently, also basic inquirers are satisfiers. However, I shall not go into this possibility here.

\section{REFERENCES}

Bromberger, $\mathrm{S}$.

1985 "On Pragmatic and Scientific Explanation: Comments on Achinstein's and Salmon's Papers". Pp. 306-325 in PSA 1984, Vol. 2. East-Lansing, Michigan: The Philosophy of Science Association.

Burian, R.

1990 "The Influence of the Evolutionary Paradigm". Forthcoming in M. Hecht (ed.), Evolutionary Biology at the Crossroads. New York: Queen's College Press.

Giere, R. N.

1988 Explaining Science. A Cognitive Approach. Chicago and London: The University of Chicago Press.

Niiniluoto, 1

1984 "Finalization, Applied Science, and Science Policy." Pp. 226-243 in I. Niiniluoto, Is Science Progressive? Dordrecht, Boston, Lancaster: D. Reidel.
Niiniluoto, I.

1987 "Soveltavat tieteet tieteenfilosofian näkökulmasta." [Applied Sciences from the Point of Philosophy of Science, in Finnish]. Academia Scientiarum Fennica. Yearbook 1986-87: 137-142.

OECD

1966 "Ministerial Meeting on Science: Fundamental Research and the Policies of Government." Paris, 1966.

Roughgarden, J., May, R. M., and Levin, S. A.

1989 "Introduction." Pp. 3-10 in Roughgarden, J., May, R. M., and Levin, S. A. (eds.), Perspectives in Ecological Theory. Princeton: Princeton University Press.

Sintonen, $M$.

1989 "Explanation: In Search of the Rationale", Pp 253282 in P. Kitcher and W. Salmon (eds.), Scientific Explanation. Minnesota: Minnesota University Press.

Sintonen, $M$.

1990 "The Many Faces of Interdisciplinarity", forthcoming in J. Ehrnrooth and L. Siurala (eds.), Construction of Youth. Helsinki: Valtion Painatuskeskus.

Slobodkin, L. B.

1988 "Intellectual problems of applied ecology." Bioscience, 38, 5: $337-342$.

Wade, $\mathrm{N}$.

1973 "Agriculture: Critics find basic research stunted and wilting." Science, 180: 390-93.

Matti Sintonen

Department of Philosophy

University of Helsinki

00170 Helsinki

Finland 